\title{
Fatigue small crack propagation analysis of aero-aluminium alloy considering crack tip plasticity
}

\author{
Guangming Kong1, Xuexia Gao2, Xudong Li1, Zhitao Mu1 \& Tao Liu1 \\ ${ }^{1}$ Naval Aeronautical Engineering Academy Qingdao Campus, Qingdao, 266041, China
}

${ }^{2}$ Qingdao University, Qingdao, 266000, China

Keywords: aluminum alloy, fatigue small crack, crack tip plasticity, crack propagation rate.

\begin{abstract}
An appropriate fatigue crack growth model is the key to accurately evaluate fatigue life of component. Researching on the McEvily model, considering the influence of elastic-plastic behaviour and crack closure, a modified elastic-plastic small crack propagation characterization model is proposed. The effects of parameters on growth rate of fatigue crack was studied using scanning electron microscopy (SEM) in-situ observation by experimental results on 6151-T6 aluminium alloy. Results indicate that the modified model is able to characterize small crack propagation behaviour, expanding the region to be precisely predicted, which is remarkably important for fatigue life prediction and damage tolerant analysis of aluminium structure.
\end{abstract}

\section{Introduction}

Aero-aluminium alloys has a low density and high strength, which is widely used in aircraft structure, but the crack propagation behaviours of fatigue small cracks and fatigue long cracks are quite different, despite the fact that most of the fatigue lifetime is spent in the short crack range. The macro fracture mechanics can not be employed to deal with short crack because of the randomcity of its propagation rate [1], so it is necessary to draw attention to the fatigue crack growth behaviour of short cracks.

McEvily and Ishihara[2] conquered the boundedness of Paris model which only applicable for middle linear propagation region of the crack growth rate curve and does not consider mean stress effect and load sequence, and then proposed a modified linear-elastic analysis of fatigue crack growth model expressed as follows:

$$
\frac{d a}{d N}=A\left(\Delta K_{e f f}-\Delta K_{e f f t h}\right)^{2}
$$

Where, $A$ is a constant which depends on the environment and the material; $\Delta K_{\text {eff }}$ is the effective range of the stress intensity factor, which is equal to $\Delta K_{\text {eff }}=K_{\max }-K_{o p}, K_{\max }$ being the maximum values of SIF and $K_{o p}$ being the value of the SIF at the crack opening level.

In order to use Eq. (1) in the analyses of small crack growth behaviour; McEvily introduced three modifications:

(1) Considering the elastic-plastic behaviour of small cracks. As the crack tip plastic zone size is large with respect to the crack length, Irwin and Dugdale [3, 4] proposed the modified crack

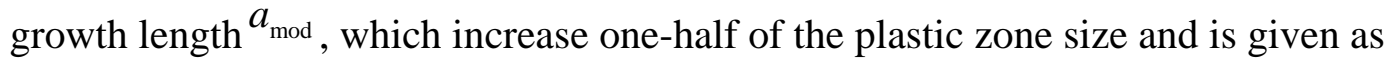

$$
a_{\text {mod }}=a+\frac{1}{2}\left(\sec \frac{\pi}{2} \cdot \frac{\sigma_{\max }}{\sigma_{s}}-1\right) \cdot a=\frac{a}{2}\left(\sec \frac{\pi}{2} \cdot \frac{\sigma_{\max }}{\sigma_{s}}+1\right)
$$

(2) Considering the variation of the crack closure level.

The following equation has been proposed to describe the development of crack closure in the wake of a newly formed crack:

$$
K_{o p}=\left(1-e^{-k a}\right)\left(K_{o p \max }-R K_{\max }\right)
$$

Where, $K_{o p \max }$ is the crack opening level for a macroscopic crack $(\mathrm{MPa} \sqrt{m}) ; k$ reflects the rate 
at which crack closure develops with increase in crack length $\left(\mathrm{m}^{-1}\right)$ 。

(3) Modified expression for stress intensity factor [5,6].

Accounting for elastic-plastic behaviour, the stress intensity factor $\Delta K$ could be modified as follows:

$$
\Delta K=\left[\sqrt{\pi r_{e}\left(\sec \frac{\pi}{2} \frac{\sigma_{\max }}{\sigma_{s}}+1\right)}+Y \sqrt{\frac{\pi}{2} a\left(\sec \frac{\pi}{2} \frac{\sigma_{\max }}{\sigma_{s}}+1\right)}\right] \sigma
$$

Where ${ }^{r}$ is the size of an inherent flaw; $\sigma_{\max }$ is the maximum stress and $Y$ is a geometrical factor

Putting the eq. (2), eq. (3) and eq. (4) into the eq. (1), and getting the fatigue samll crack propagation model as follows:

$$
\begin{aligned}
M & =\Delta K_{\text {eff }}-\Delta K_{\text {effth }} \\
& =K_{\text {max }}-K_{o p}-\Delta K_{\text {effh }} \\
& =\sqrt{\pi r_{e}\left(\sec \frac{\pi}{2} \cdot \frac{\sigma_{\max }}{\sigma_{s}}+1\right)}\left(1+Y \sqrt{\frac{a}{2 r_{e}}}\right) \sigma_{\text {max }}(1-R)-\left(1-e^{-k a}\right)\left(K_{\text {op } \max }-R K_{\max }\right)-\Delta K_{\text {effh }}
\end{aligned}
$$

In order to improve the forecast ability of McEvily model, eq. (5) is modified as follows:

$$
\frac{d a}{d N}=A M^{\varphi}
$$

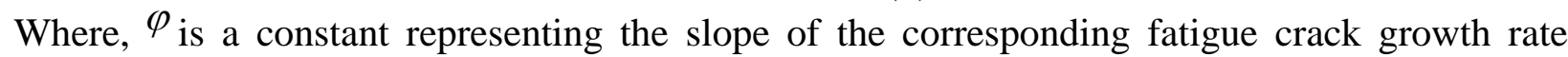
curve, and $A$ is a material and environmentally sensitive constant.

Eq. (7) represents the driving force for small crack propagation $M$, In order to evaluate this parameter the following material constants are needed: $A, r_{e}, k, \varphi, K_{o p \max }$.

\section{Experimental method}

The material used was 6151-T6 aluminium alloy, which chemical composition and mechanical properties are shown in Table 1. The aero-aluminium alloy was machined as the dog-bone shaped specimen, whose shape and size was shown in Fig.1. In order to facilitate the observation, a notch with a radius of about $0.05 \mathrm{~mm}$ was made locating at the centre of the gage length.

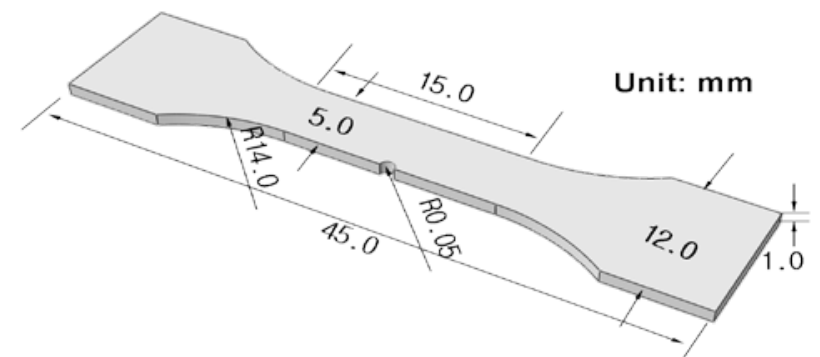

Fig. 1 Schematic diagram of shape and dimension of 6151-T6 specimen

Table 1 The chemical composition and static strength properties of AA 6151-T6

\begin{tabular}{ccccccccc}
\hline $\begin{array}{c}\text { Composition } \\
\text { (Wt. \%) }\end{array}$ & $\mathrm{Cu}$ & $\mathrm{Mn}$ & $\mathrm{Mg}$ & $\mathrm{Zn}$ & $\mathrm{Al}$ & $\begin{array}{c}\sigma_{0.2} \\
(\mathrm{MPa})\end{array}$ & $E$ (Gpa) & $\begin{array}{c}\sigma_{b} \\
(\mathrm{MPa})\end{array}$ \\
\hline $6151-\mathrm{T} 6$ & 0.5 & 0.35 & 0.66 & 0.2 & Balance & 255 & 54.4850 & 290 \\
\hline
\end{tabular}

Fatigue tests were conducted at room temperature in the chamber of SS550 SEM combining a 
specially designed servo hydraulic testing system at a frequency of $10 \mathrm{~Hz}$. The fatigue small crack propagation tests of all specimens were carried out at a stress ratio $R=0.1$ and three stresses levels (200, 220 and $240 \mathrm{MPa}$, respectively). And then, the fracture surfaces of all the broken specimens were observed using a field-emission type scanning electron microscope (FE-SEM)[7].

\section{Results and discussion}

Linear Elastic Fracture Mechanics has been successfully applied to quantify growth rates of cracks under cyclic loads. The fatigue crack growth life can be described by the Paris power law:

$$
\frac{\mathrm{d} a}{\mathrm{~d} N}=C(\Delta K)^{m}
$$

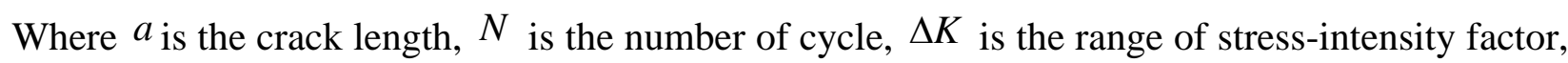
and $f(a / W)$ is a crack-shape correction factor.

Fatigue small crack propagation curves under different stress levels are shown in Fig.2. As can be seen from the figure, it can be found that the crack growth rate fluctuates in stronger randomness, and the linear-elastic parameter was not an effective correlating parameter for the experimental results.

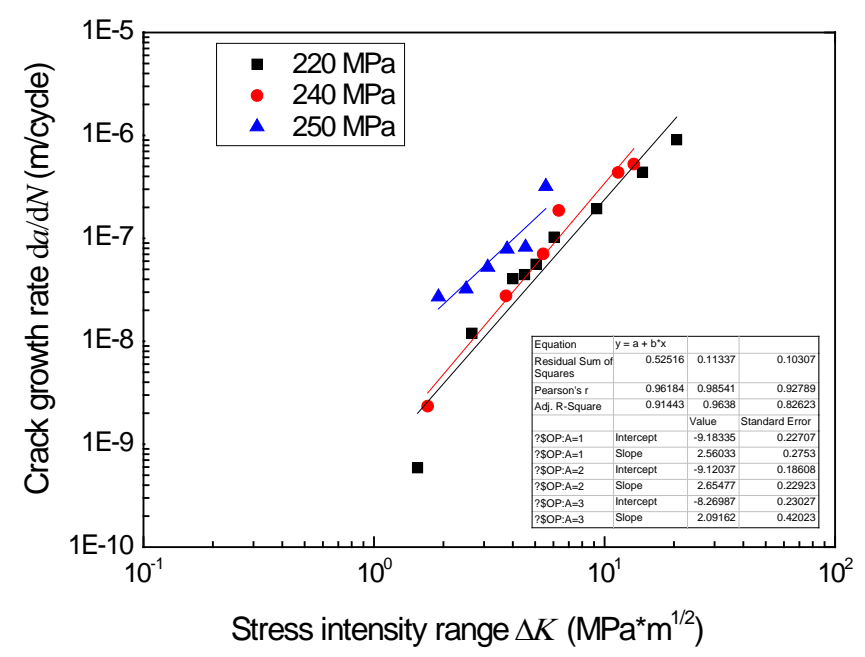

Fig. 2 The rate of fatigue Crack propagation as a function of $\Delta \mathrm{K}$ under different stress levels

So, it's necessary to establish a nonlinear equation based on the McEvily model, and give error function as follows

$$
\text { Error }=\sum_{i=1}^{n}\left[\left(\frac{d a}{d N}\right)_{i}-\left\{A M^{\varphi}\right\}_{i}\right]^{2}
$$

Considering the genetic algorithm could be effectively solve multi-modal optimization problems, the parameters of the fatigue crack growth rate model can be determined through the genetic algorithm based on the experimental data. Firstly, setting the initial population $\left(A_{0}, \varphi_{0}, k_{0}, r_{e 0}, K_{o p \max 0}\right)$ which were selected based on optimization criteria. And then the mutant evolution course randomness in order to efficiency of searching for the new populations $\left(A_{i}, \varphi_{i}, k_{i}, r_{e i}, K_{o p \max i}\right)$. Setting the objective function the error function, the global optimal individual will be searched.

The fitting results and the corresponding experimental data for different load ratios are shown in Fig.4, and the parameters under different load levels will exist as shown in Table 2. In comparison with Fig.2, a much better correlation between predictions and it was show that the proposed model improves the accuracy of the predictions, effectively solves the data unbalance problem, and it is an 
effective method to predict the fatigue lifetime

Tab.2 The parameters of crack growth rate of 6A02 aluminum alloy

\begin{tabular}{|c|c|c|c|c|c|c|}
\hline \multirow{2}{*}{\multicolumn{2}{|c|}{ Parameter }} & A & $\varphi$ & $k$ & $r_{e}$ & $K_{o p \max }$ \\
\hline & & $(\mathrm{MPa})^{1 / 2}$ & & $\mathrm{~m}^{-1}$ & $\mathrm{~m}$ & $\mathrm{MPa} \sqrt{\mathrm{m}}$ \\
\hline \multirow{3}{*}{$\begin{array}{l}\text { Optimu } \\
\text { m } \\
\text { estimati } \\
\text { on value }\end{array}$} & 220MPa & $\begin{array}{c}9.892 \times 10- \\
9\end{array}$ & 1.46 & 7000 & $\begin{array}{c}0.6 \mathrm{e} \times 10- \\
6\end{array}$ & 3.20 \\
\hline & $240 \mathrm{MPa}$ & $4.32 \times 10-8$ & 1.32 & 6300 & $\begin{array}{c}2.1 \mathrm{e} \times 10- \\
6\end{array}$ & 2.80 \\
\hline & $250 \mathrm{MPa}$ & $9.64 \times 10-9$ & 2.02 & 9000 & $\begin{array}{c}5.2 \mathrm{e} \times 10- \\
6\end{array}$ & 4.30 \\
\hline
\end{tabular}

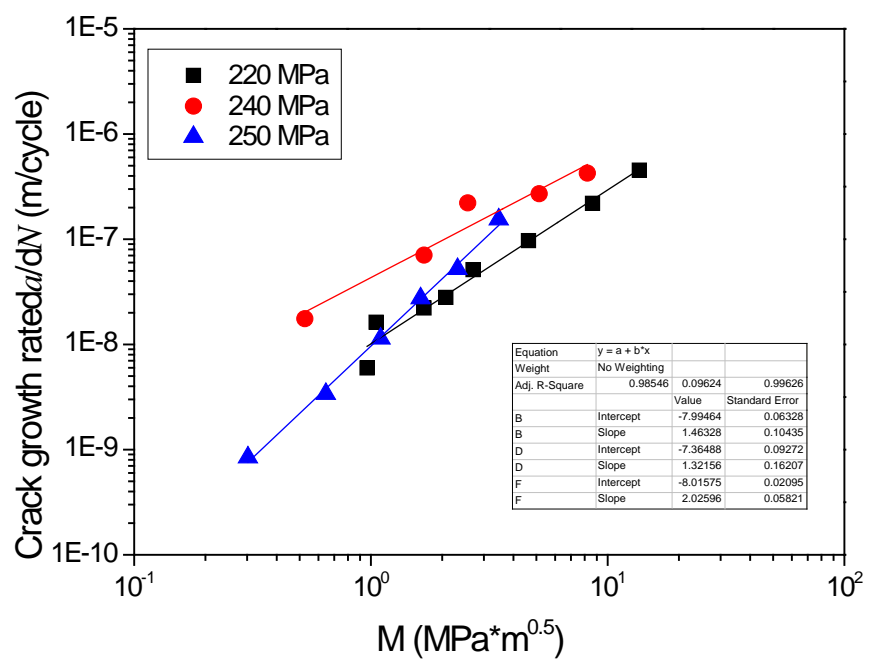

Fig. 4 The rate of fatigue crack growths as a function of the parameter $\mathrm{M}$ of different stress levels

\section{Conclusion}

(1) Based on the McEvily model, considering elastic-plastic behaviour, the development of crack closure, the relation between the threshold for fatigue crack growth and the endurance limit, the Evaluation of fatigue small crack growth rate model can be established. Results indicate that the modified model is able to characterize small crack propagation behaviour, expanding the region to be precisely predicted.

(2) The experimental results are in good agreement with predictions of amendment fatigue crack growth rate model. The proposed model based on McEvily model is reasonable, and proposed a theoretical reference for aluminium alloy damage tolerance analysis.

\section{References}

[1] LI Xudong, LIU Zhiguo, MU Zhitao. Fatigue crack growth of LD10CZ aluminum alloy with pre-corrosion based on micro-crack. Journal of Naval Aeronautical and Astronautical University, 2013, 28(1): 47-52

[2] A.J.McEvily, D.Eifler, E. Macherauch, Eng. Fract. Mech. 1991(40): 571-584

[3] Paris PC, Erdogan F. A critical analysis of crack propagation laws. Trans ASME J Basic Eng, 1963, 85: 528-534

[4] Matos PFP, McEvily AJ, Moreira PMGP, Castro PMST. Analysis of the effect of cold-working of rivet holes on the fatigue life of an aluminum alloy. Fatigue 2007, 29: 575-86 
[5] McEvily A J, Ishihara S. On the dependence of the rate of fatigue crack growth on the $\sigma_{a}^{n}(2 a)$ parameter. International Journal of Fatigue.2001 (23): 115-120.

[6] McEvily A J, Ishihara S, Endo M. An analysis of multiple two-step fatigue loading. International Journal of Fatigue, 2005, 27: 862-866.

[7] Wang XS, Fan JH. SEM online investigation of fatigue crack initiation and propagation in notched cast magnesium specimens. Journal of Materials Science, 2004, 39(7): 2617-2620. 